\title{
Normalization of the Verbal Fluency Test on the basis of results for healthy subjects, patients with schizophrenia, patients with organic lesions of the chronic nervous system and patients with type 1 and 2 diabetes
}

\author{
Adam Wysokiński, Krzysztof Zboralski, Agata Orzechowska, Piotr Gałecki, Antoni Florkowski, \\ Monika Talarowska
}

Clinic of Adult Psychiatry, Second Department of Diseases of the Nervous System, Medical University of Lodz, Lodz, Poland

Submitted: 30 January 2009

Accepted: 1 May 2009

Arch Med Sci 2010; 6, 3: 438-446

DOI: 10.5114/aoms.2010.14268

Copyright @ 2010 Termedia \& Banach

\section{Abstract}

Introduction: Verbal fluency is the ability to form and express words compatible with required criteria. Verbal fluency is necessary for optimal communication and for normal social and occupational functioning. The Verbal Fluency Test is a good indicator of frontal lobe dysfunction, particularly of the left frontal cortex. Material and methods: The aim of the study was to compare verbal fluency in healthy subjects $(n=50)$, patients with paranoid schizophrenia $(n=36)$, patients with organic lesions of the central nervous system (CNS) $(n=33)$, and patients with diabetes $(n=62)$ - type 1 diabetes $(n=31)$ and type 2 diabetes $(n=31)$. Results: Healthy subjects and patients with diabetes achieved the highest results in all categories of the Verbal Fluency Test. Patients with paranoid schizophrenia achieved significantly lower results. Sten norms of the Verbal Fluency Test were developed for the general population. Using these norms it was found that subjects with schizophrenia or with organic lesions of the CNS had very poor results more often and very high results less frequently compared to healthy subjects and also to patients with diabetes.

Conclusions: This observation is consistent with the neurodevelopmental hypothesis of schizophrenia, in which cognitive functions of the frontal lobe (e.g. verbal fluency) play a major role in the psychopathological picture. We have also demonstrated that in patients with type 1 and 2 diabetes verbal fluency is comparable with healthy subjects.

Key words: Verbal Fluency Test, schizophrenia, organic lesions, diabetes.

\section{Introduction}

Verbal fluency is defined as the ability to form and express words in accordance with required criteria. Disorders of verbal fluency may take the form of verbal perseverations or forming words that do not belong to a required category. A normal level of verbal fluency is necessary for optimal communication and, therefore, for normal social and occupational functioning. The Verbal Fluency Test is a commonly accepted and widely applied test, used for assessing verbal fluency. The reliability of this test has been demonstrated by other authors and a high level of internal coherence was found $(r$-Pearson $=0.85)$ [1]. The number of words in each

\author{
Corresponding author: \\ Adam Wysokiński, MD \\ Clinic Of Adult Psychiatry \\ Medical University of Lodz \\ Unit XIB \\ J. Babiński Hospital \\ Aleksandrowska 159 \\ 91-229 Lodz, Poland \\ Phone: +48 42 652-12-89 \\ Fax: +48 42 640-50-52 \\ E-mail: \\ adam.wysokinski@gmail.com
}


category is consistent with the efficacy of all aspects of the studied variable (the higher the result, the higher the efficacy of these functions).

The results of the Verbal Fluency Test are a good diagnostic indicator of frontal lobe dysfunction [2]. The Verbal Fluency Test, similarly to other tests that assess executive functions (Wisconsin Card Sorting Test, Trail Making Test), is a sensitive tool, which enables one to detect dysfunctions of the frontal lobes, particularly of the left frontal cortex [3]. Poor results of the Verbal Fluency Test may also be associated with dysfunctions of the temporal cortex and prefrontal cortex of the left hemisphere. Area 44 and 45 situated within the inferior frontal gyrus (Broca's region) and dorsolateral prefrontal cortex of the left hemisphere are activated while performing this test [4]. The inferior part of the left prefrontal cortex is activated while executing the letter test, while the anteroinferior part of the prefrontal cortex is activated while executing the category test [5].

Disorders of cognitive functions, including executive functions, for example verbal fluency, are often present in subjects with schizophrenia. Disorders of the working memory and executive functions are the fundamental and established deficit, which may become intensified in the course of the disease [6]. This has a significant effect on the efficacy of other cognitive functions and determines adaptability of patients. These deficits are present before the onset of schizophrenia and become more intense during the first episode of schizophrenia. Their presence before the onset of symptomatic psychosis supports the neurodevelopmental hypothesis of schizophrenia, according to which genetic and environmental factors take part in the aetiopathogenesis of this disease. Interactions of these factors at early stages of the development of the central nervous system may have disadvantageous effects on neuron growth and cytoarchitectonics of the brain cortex. These abnormalities develop during fetal development and early childhood and are expressed in the form of schizophrenia after puberty [7]. They are significantly more intense in patients who did not undergo medical treatment during the first period of psychosis. Longer duration of untreated psychosis is associated with higher risk of permanent global cognitive deficits [8]. Disorders of verbal functions in subjects with schizophrenia are strictly associated with disorders of information processing processes, executive functions and memory processes. They are present in subjects with schizophrenia in the prodromal period, as well as in their first-degree relatives. The latter observation is consistent with the neurodevelopmental hypothesis of schizophrenia. Decreased verbal fluency in this group of patients is expressed in the form of numerous perseverations, neologisms and listing words that do not belong to a required category [9].

Patients with diabetes are a group in which involutive processes occur earlier and progress faster (this also applies to cognitive functioning) [10]. In the group of patients aged > 60 years a significant decline of cognitive functions compared to healthy subjects was found 4 years after diagnosis of diabetes [11]. Strachan et al. [12] found that cognitive disorders are more frequent in patients with diabetes than in subjects at the same age without diabetes. Also in patients with an abnormal glucose curve (but without symptomatic diabetes) increased frequency of mild cognitive disorders was found [13]. According to other authors [14] diabetes increases the risk of dementia (both vascular and Alzheimer's) two-fold. Cukierman et al. [15] suggested that cognitive disorders should be included in the group of chronic complications of diabetes. Diabetes (type 1 and 2) causes disorders of verbal and spatial memory, efficacy of attention processes, verbal fluency and functions that depend on the frontal lobes (associative functions), and psychomotor dexterity, and is associated with increased risk of intellectual disorders [16-20].

The objective of this research was to evaluate verbal skills in a group of healthy subjects, patients with paranoid schizophrenia, patients with type 1 and 2 diabetes, and patients with diagnosed organic lesions of the central nervous system (CNS). On the basis of the results the authors carried out normalization of the Verbal Fluency Test. The authors have developed a sten scale which enables psychologists and psychiatrists to assess qualitatively the results of the Verbal Fluency Test. Moreover, the presence of normalization allows researchers to compare obtained results with a reference group (the general population).

\section{Material and methods}

One hundred and eighty-one subjects (men $n=105[58.01 \%]$ ) aged $18-55$ years participated in the study. Mean age of all studied subjects was $38.37 \pm 12.18$ years. The participants of the study were divided into 6 groups: healthy subjects ( $n=50$; men $n=25$ [50.0\%]; mean age $31.52 \pm 9.30$ years), patients with paranoid schizophrenia ( $n=36$; men $n=27$ [75.0\%]; mean age $35.83 \pm 13.87$ years), patients with diagnosed organic lesions of the CNS ( $n=33$; men $n=22$ [66.7\%]; mean age $43.91 \pm 11.23$ years), patients with diabetes $(n=62$; men $n=31$ [50.0\%]; mean age $42.42 \pm 10.78$ years), who were divided into two subgroups: patients with type 1 diabetes ( $n=31$; men $n=8$ [25.5\%]; mean age $38.10 \pm 11.64$ years) and patients with type 2 diabetes ( $n=31$; men $n=23$ [74.2\%]; mean age $46.74 \pm 7.88$ years). 
Exclusion criteria for the schizophrenia group were: the presence of any organic lesions of the central nervous system and coexisting somatic diseases, including diabetes. Exclusion criteria for the CNS lesion group were: the presence of somatic diseases, including diabetes, and diagnosis of schizophrenia or other schizophrenia-like psychoses. Exclusion criteria for the combined diabetes group (and therefore for type 1 and type 2 groups) were: the presence of organic lesions in the central nervous system, schizophrenia or other schizophrenia-like psychoses. Mean PANSS score in the group of schizophrenic patients was 68.67 \pm 28.83 points. Treatment duration in that group was $\geq 4$ weeks (mean $72.07 \pm 42.68$ weeks). The patients in that group were treated with typical and atypical antipsychotics. The numbers of patients treated with individual antipsychotics were small and therefore these variables were excluded from further analysis. Central nervous system lesions were diagnosed on the basis of neuroimaging examinations (computer tomography and/or magnetic resonance imaging) and neuropsychological examination carried out before the study. Treatment duration in the combined group of patients with diabetes, type 1 diabetes and type 2 diabetes were $158.52 \pm 122.92,176.13 \pm 162.05$, and $140.90 \pm 61.81$ weeks, respectively. Mean glycated haemoglobin $\left(\mathrm{HbA}_{1 \mathrm{c}}\right)$ levels in the combined group of patients with diabetes, type 1 diabetes and type 2 diabetes were $9.47 \pm 2.69,9.17 \pm 1.46$, and 9.78 $\pm 3.56 \%$, respectively. All patients were examined for the presence of mood disorders. Only patients without depression and mania were included in the study groups. Participants of the study had no IQ test carried out; however, none of the patients had

Table I. Academic level of the study participants

\begin{tabular}{|lccc|}
\hline Group & $\begin{array}{c}\text { Primary } \\
\text { or vocational } \\
n(\%)\end{array}$ & $\begin{array}{c}\text { Secondary } \\
n(\%)\end{array}$ & $\begin{array}{c}\text { Higher } \\
n(\%)\end{array}$ \\
\hline $\begin{array}{l}\text { Healthy subjects } \\
(n=50)\end{array}$ & $4(8.0 \%)$ & $22(44.0 \%)$ & $24(48.0 \%)$ \\
\hline $\begin{array}{l}\text { Schizophrenia } \\
(n=36)\end{array}$ & $11(30.6 \%)$ & $21(58.3 \%)$ & $4(11.1 \%)$ \\
\hline $\begin{array}{l}\text { CNS lesions } \\
(n=33)\end{array}$ & $14(42.4 \%)$ & $16(48.5 \%)$ & $3(9.1 \%)$ \\
\hline $\begin{array}{l}\text { Diabetes } \\
(n=62)\end{array}$ & $19(30.7 \%)$ & $33(53.2 \%)$ & $10(16.1 \%)$ \\
\hline $\begin{array}{l}\text { Type } 1 \\
(n=31)\end{array}$ & $6(19.4 \%)$ & $19(61.3 \%)$ & $6(19.3 \%)$ \\
\hline $\begin{array}{l}\text { Type } 2 \\
(n=31)\end{array}$ & $13(41.9 \%)$ & $14(45.2 \%)$ & $4(12.9 \%)$ \\
\hline $\begin{array}{l}\text { Total } \\
(n=181)\end{array}$ & $48(26.5 \%)$ & $92(50.8 \%)$ & $41(22.6 \%)$ \\
\hline
\end{tabular}

mental retardation diagnosed before participating in the study. Academic level of the study participants is presented in Table I. The authors did not normalize the results for individual academic levels as the number of subjects for these subgroups was too small. The patients were treated in accordance with current guidelines for individual diseases and the authors did not intervene in the therapeutic process. Each participant gave written informed consent. The study protocol was authorized by the ethics committee of the Medical University of Lodz.

The Verbal Fluency Test was used in the study. This test evaluates the ability to form and fluently utter words compatible with given criteria. The test consists of three parts. The first two parts consist in listing in $60 \mathrm{~s}$ as many words as possible that belong to a given semantic category (usually names of objects). In the third part the objective is to list in $60 \mathrm{~s}$ as many words as possible that belong to a given phonetic category - words beginning with a given letter. In the present study these categories were: names of animals (category 1), names of sharp objects (category 2) and words beginning with the letter $\mathrm{K}$ (category 3 ). The result of the test is the number of correct words listed for each of the categories.

Obtained results were analysed statistically using ANOVA method and post-hoc tests. Statistical analysis was carried out using STATISTICA 7.0 PL software.

\section{Results}

Detailed results of the Verbal Fluency Test for individual categories are presented in Table II. Using the Levene test of uniform variances it was found that all groups are unified in terms of analysed variables $-p$-values for category 1,2 and 3 were $0.055,0.725$ and 0.472 , respectively. To evaluate differences between average results achieved by subjects in each category ANOVA analysis was used. The analysis revealed statistically significant differences of means between individual groups for each Verbal Fluency Test category: names of animals: $F=11.056, \mathrm{~d} f=5, p<0.0001$; names of sharp objects: $F=6.497, \mathrm{~d} f=5, p<0.0001$; words beginning with the letter $\mathrm{K}: F=9.931, \mathrm{~d} f=5$, $p<0.0001$.

Obtained results were analysed using the posthoc Scheffe test in order to evaluate the presence of statistically significant differences between individual groups. For category 1 ("names of animals") we found that the lowest results were achieved in the groups of patients with schizophrenia and with CNS lesions ( $p<0.05$ vs. healthy subjects, patients with type 1 diabetes and combined diabetes group). There were no significant differences between the results of 
Table II. Results of the Verbal Fluency Test

\begin{tabular}{|c|c|c|c|c|c|c|c|c|c|}
\hline \multirow[t]{2}{*}{ Group } & \multicolumn{3}{|c|}{ Names of animals } & \multicolumn{3}{|c|}{ Names of sharp objects } & \multicolumn{3}{|c|}{ Words beginning with the letter $\mathrm{K}$} \\
\hline & Mean & SD & Range & Mean & SD & Range & Mean & SD & Range \\
\hline $\begin{array}{l}\text { Healthy subjects } \\
(n=50)\end{array}$ & 26.44 & 8.73 & $11-45$ & 13.18 & 4.27 & $5-21$ & 19.08 & 6.59 & $8-37$ \\
\hline $\begin{array}{l}\text { Schizophrenia } \\
(n=36)\end{array}$ & 16.69 & 3.39 & $7-30$ & 8.72 & 3.62 & $1-17$ & 13.39 & 4.84 & $1-21$ \\
\hline $\begin{array}{l}\text { CNS lesions } \\
(n=33)\end{array}$ & 16.91 & 5.66 & $7-28$ & 9.33 & 4.24 & $3-21$ & 12.76 & 5.96 & $3-33$ \\
\hline $\begin{array}{l}\text { Diabetes } \\
(n=62)\end{array}$ & 22.87 & 7.64 & $11-42$ & 11.64 & $5-23$ & 4.18 & 18.79 & 5.66 & $5-31$ \\
\hline $\begin{array}{l}\text { Type } 1 \\
(n=31)\end{array}$ & 24.32 & 7.71 & $13-42$ & 11.71 & 4.06 & $5-23$ & 19.19 & 5.23 & $9-31$ \\
\hline $\begin{array}{l}\text { Type } 2 \\
(n=31)\end{array}$ & 21.42 & 7.41 & $11-41$ & 11.58 & 4.36 & $6-21$ & 18.39 & 6.13 & $5-29$ \\
\hline $\begin{array}{l}\text { Total } \\
(n=181)\end{array}$ & 21.54 & 8.37 & $7-45$ & 11.07 & 4.43 & $1-23$ & 16.70 & 6.46 & $1-37$ \\
\hline
\end{tabular}

SD - standard deviation, CNS - central nervous system

healthy subjects and patients with diabetes or between patients with type 1 and type 2 diabetes. The results of patients with type 2 diabetes did not significantly differ from the results of patients with schizophrenia or CNS lesions. For category 2 ("names of sharp objects") we found that the results of patients with schizophrenia were significantly lower $(p<0.05)$ than those of healthy subjects, patients with type 1 and type 2 diabetes and the combined diabetes group. The results of patients with CNS lesions were significantly lower $(p<0.05)$ than those of healthy subjects, but not schizophrenic or diabetic patients (or type 1 and type 2 diabetes subgroups). Again, there were no significant differences between the results of healthy subjects and patients with diabetes or between patients with type 1 and type 2 diabetes. For category 3 ("words beginning with the letter K") the results were similar to those observed for category 1 . The only difference was that the results for patients with type 2 diabetes were also significantly higher $(p<0.05)$ than those for patients with schizophrenia or CNS lesions. Figures 1-3 present the values of the median, $25-75 \%$ range and min-max for individual categories of the Verbal Fluency Test for all studied groups.

On the basis of obtained results the authors developed a sten scale for each category of the Verbal Fluency Test. The sten (standard ten) scale is a scale of the following characteristics: mean $=5.5$, standard deviation $=2.0$. It has ten items (stens). Each item represents 0.5 standard deviation and a certain percentage of the area under the curve of the normal distribution of results. Items 1-2 represent very low results;
3-4 - low results; 5-6 - average results; 7-8 - high results; and 9-10 - very high results.

Raw scores for each category of the Verbal Fluency Test were transformed statistically. First, we calculated the cumulative number of patients for each score (cf). Next, of values were multiplied by $1 / n(n=181)$. Then, the results were transformed into sten scores using the transformation table described in [21]. Developed sten scores are presented in Table III. Using this table it is possible to convert raw results for each category into sten scores. Subsequently, these scores may be described qualitatively. This makes describing observed results easier and clearer. Moreover, using sten scores it is possible to make qualitative comparisons between different populations. Using the developed sten scale we have analysed the results obtained for individual categories of the Verbal Fluency Test. Appropriate sten scores were attributed to individual patients' results on the basis of the developed sten scale. Next, the number of patients from individual groups who achieved the same sten score for a particular category was analysed. This enabled us to compare sten scores of the studied groups. Figures 4-5 present the number of subjects from each studied group for individual values of the sten scale.

\section{Discussion}

Healthy subjects and patients with diabetes (type 1 and 2) achieved the highest results in all categories of the Verbal Fluency Test. In the case of patients with paranoid schizophrenia and patients with organic lesions of the CNS the results obtained by these patients were compatible with 


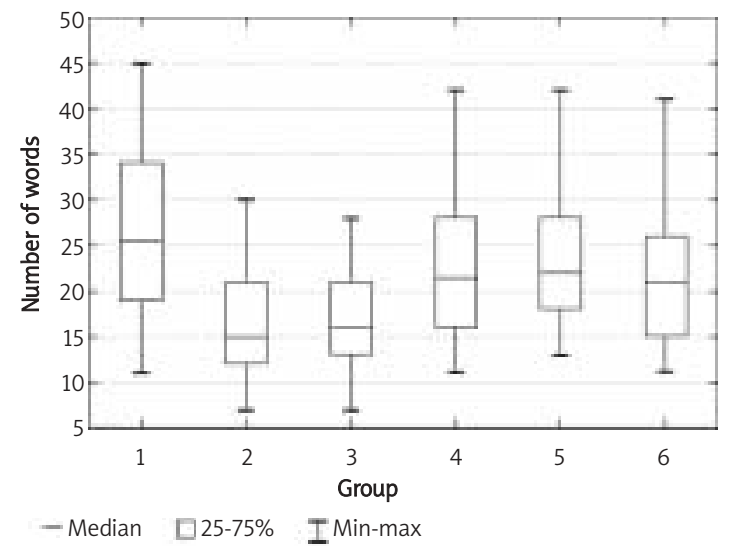

Group 1 - healthy subjects, group 2 - subjects with schizophrenia, group 3 - subjects with organic lesions of the central nervous system, group 4 - subjects with diabetes (type 1 and 2), group 5 - subjects with type 1 diabetes, group 6 - subjects with type 2 diabetes

Figure 1. Median, $25-75 \%$ range, min-max for Verbal Fluency Test category 1 (names of animals)

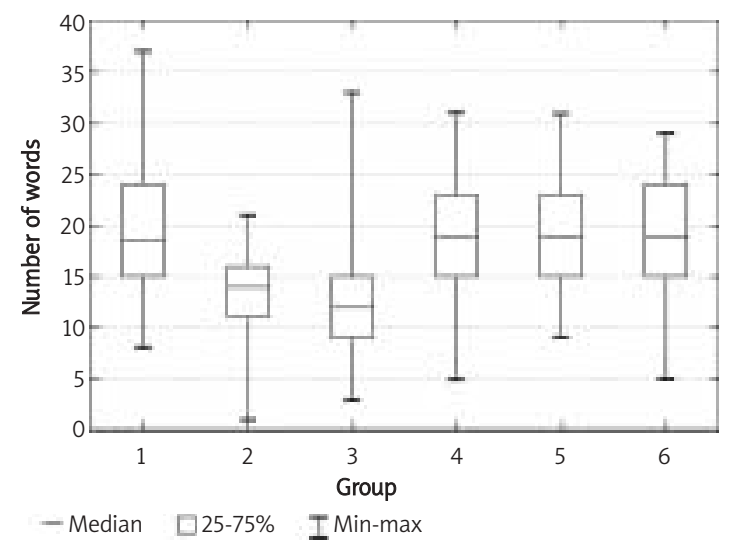

Group 1 - healthy subjects, group 2 - subjects with schizophrenia, group 3 -subjects with organic lesions of the central nervous system, group 4 - subjects with diabetes (type 1 and 2), group 5 - subjects with type 1 diabetes, group 6 -subjects with type 2 diabetes

Figure 3. Median, $25-75 \%$ range, min-max for Verbal Fluency Test category 3 (words beginning with the letter K)

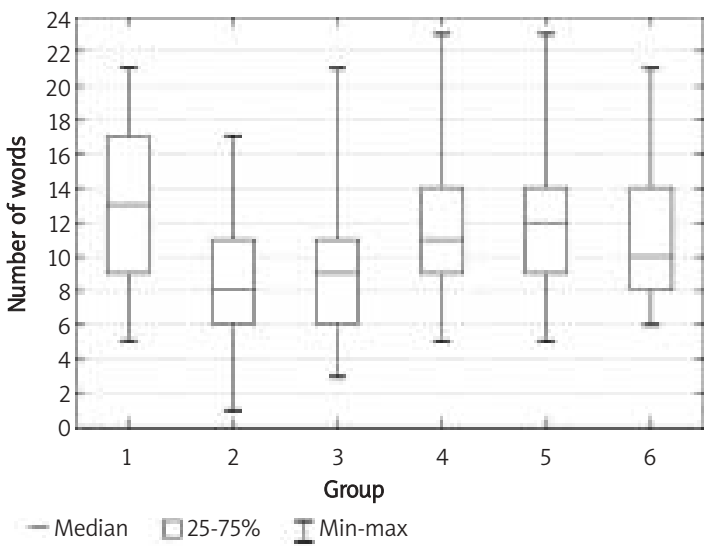

Group 1 - healthy subjects, group 2 - subjects with schizophrenia, group 3 - subjects with organic lesions of the central nervous system, group 4 - subjects with diabetes (type 1 and 2), group 5 - subjects with type 1 diabetes, group 6 - subjects with type 2 diabetes

Figure 2. Median, 25-75\% range, min-max for Verbal Fluency Test category 2 (names of sharp objects)

the results published in other papers. There were no statistically significant differences in the results for category 1 (names of animals), category 2 (names of sharp objects) and category 3 (words beginning with the letter K) between the group of patients with schizophrenia and patients with organic lesions of the CNS. In all three categories of the Verbal Fluency Test the patients belonging to these two groups (patients with schizophrenia and with organic lesions) obtained significantly lower results than did healthy subjects or, what is more interesting, patients with diabetes. Patients in these two groups obtained very low results more often and very high results less frequently for each of the three categories compared to other participants of the study.

In the case of patients with paranoid schizophrenia and with organic lesions of the CNS

Table III. Sten norms for individual categories of the Verbal Fluency Test

\begin{tabular}{|c|c|c|c|c|}
\hline \multirow[t]{2}{*}{ Sten } & \multicolumn{3}{|c|}{ Number of words } & \multirow[t]{2}{*}{ Sten } \\
\hline & $\begin{array}{c}\text { Category } 1 \\
\text { (names of animals) }\end{array}$ & $\begin{array}{c}\text { Category } 2 \\
\text { (names of sharp objects) }\end{array}$ & $\begin{array}{c}\text { Category } 3 \\
\text { (words beginning with the letter K) }\end{array}$ & \\
\hline 1 & $\leq 8$ & $\leq 3$ & $\leq 4$ & 1 \\
\hline 2 & $9-10$ & $4-5$ & $5-6$ & 2 \\
\hline 3 & $11-12$ & 6 & $7-10$ & 3 \\
\hline 4 & $13-15$ & $7-8$ & $11-13$ & 4 \\
\hline 5 & $16-20$ & $9-10$ & $14-17$ & 5 \\
\hline 6 & $21-25$ & $11-12$ & 18-19 & 6 \\
\hline 7 & $26-29$ & $13-15$ & $20-23$ & 7 \\
\hline 8 & $30-36$ & $16-18$ & $24-26$ & 8 \\
\hline 9 & $37-40$ & $19-20$ & $27-29$ & 9 \\
\hline 10 & $>40$ & $>20$ & $>29$ & 10 \\
\hline
\end{tabular}



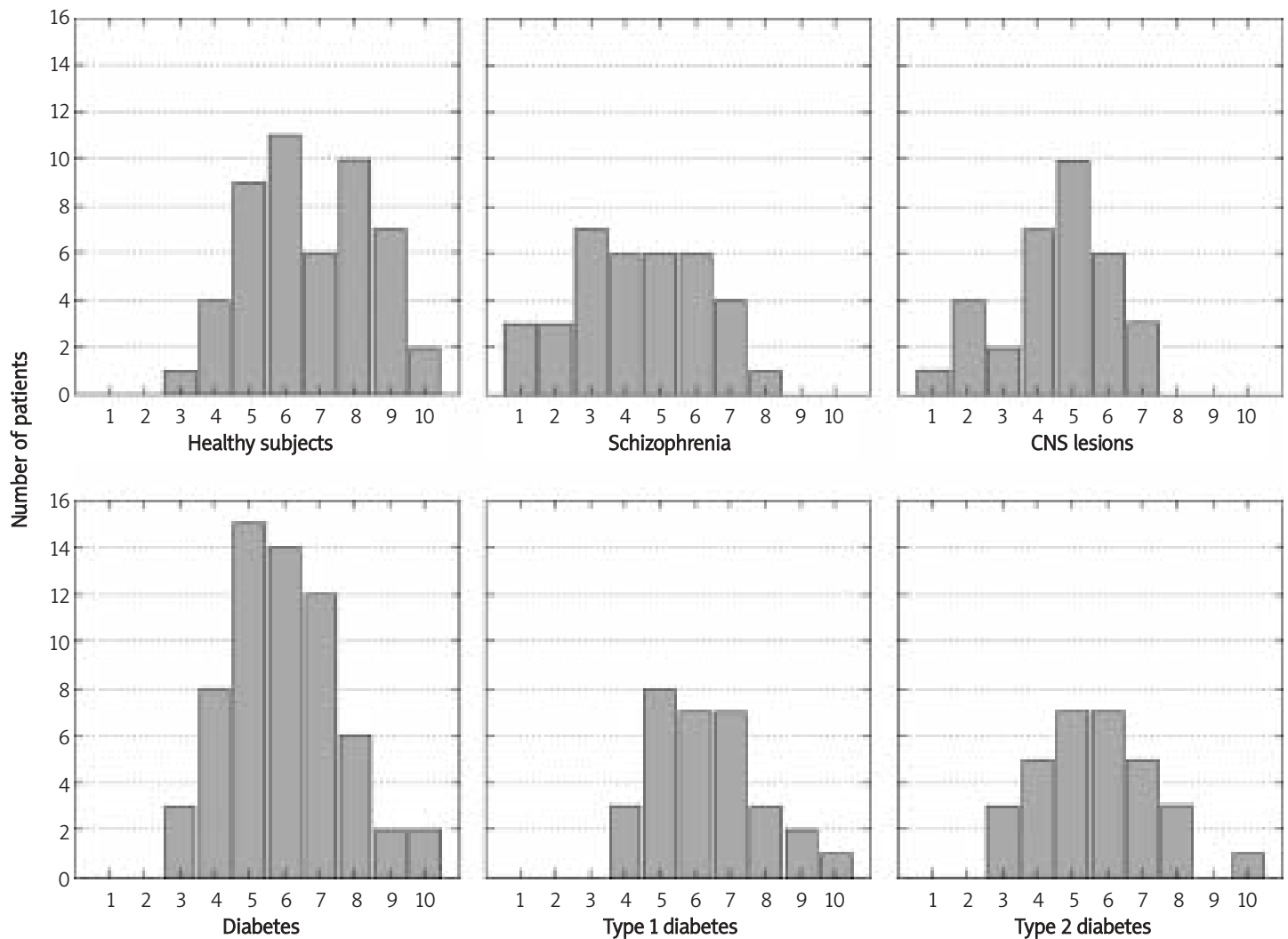

Figure 4. Sten results for Verbal Fluency Test category 1 (names of animals)
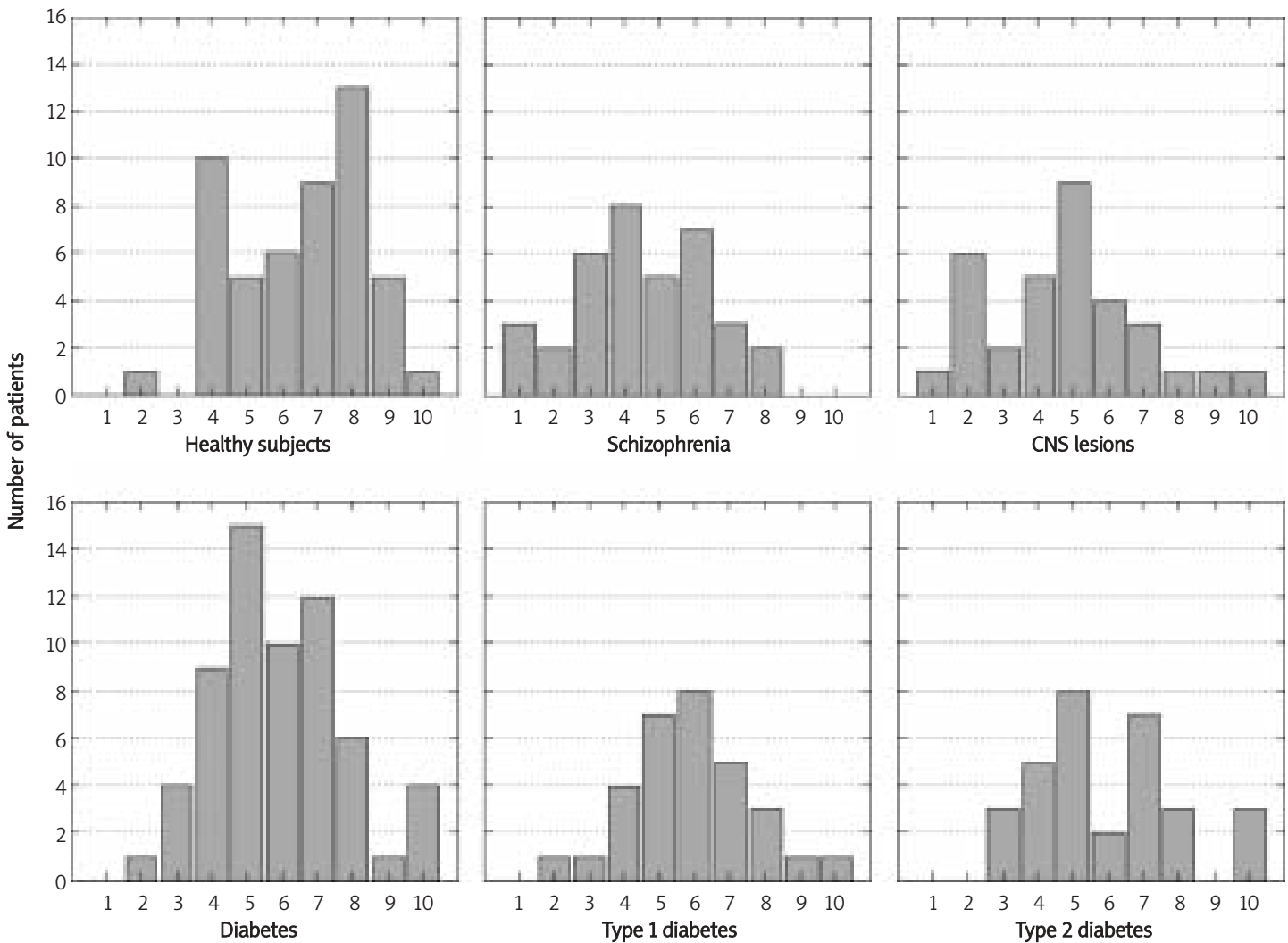

Figure 5. Sten results for Verbal Fluency Test category 2 (names of sharp objects)

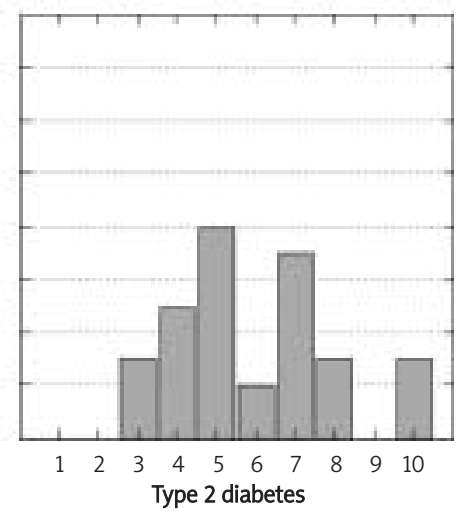



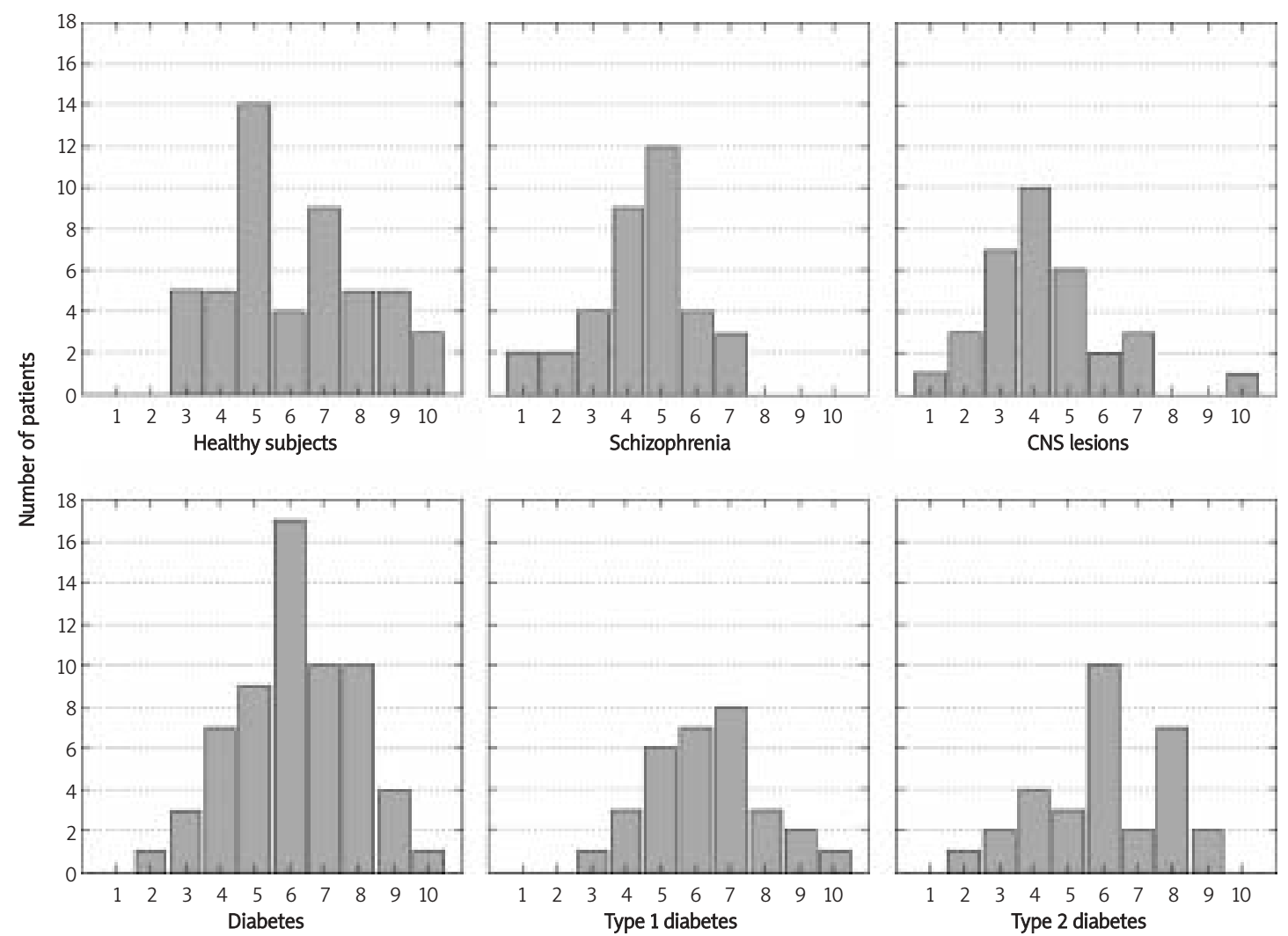

Figure 6. Sten results for Verbal Fluency Test category 3 (words beginning with the letter K)

the results for all three categories were significantly lower than the results of healthy subjects. In the case of category 1 the results were also lower than the results achieved by patients with diabetes and the results obtained in the subgroup of type 1 diabetes patients. Moreover, in these subgroups the results in category 3 were also lower than the results of the patients with type 2 diabetes. Such differences were not observed for category 2, except for a statistically significant difference between the group of patients with paranoid schizophrenia and the group of patients with diabetes.

We found no statistically significant differences between healthy subjects and patients with diabetes or between individual subgroups of patients with diabetes (type 1 and type 2). On the basis of published papers on that subject, a conclusion may be drawn that in general researchers do not agree on the extent and type of cognitive deficits that may result from diabetes (for example Lobnig et al. [22] emphasize the presence of non-significant differences in verbal fluency in both types of diabetes [type 1 and type 2], while Hsu-Ko Kuo et al. [23] report that the speed of mental processes is reduced in patients with diabetes). According to Arvanitakis et al. [16], Audenaert et al. [24], Kumari et al. [25], and Manschot et al. [18] type 2 diabetes causes disorders of verbal and spatial memory, verbal fluency, function of the frontal lobe (associative and executive functions), and psychomotor abilities, and is associated with increased risk of intellectual disorders. On the other hand, Wysocki et al. [26] and Brands et al. [27] claim that the episodes of hypoglycaemia, which are more frequent among patients with type 1 diabetes, may lead to the deterioration of cognitive functions, but these changes are usually short-lasting and transitory. Yeung et al. [28] reported that there are no changes of verbal fluency in the course of diabetes, while Gallacher et al. [29] and Kanaya et al. [30] reported the presence of negative effects of diabetes on the efficacy of verbal fluency. Our results seem to confirm the former observation.

In conclusion, patients with paranoid schizophrenia and subjects with organic lesions of the central nervous system achieved significantly lower scores in the Verbal Fluency Test compared to healthy subjects and patients with diabetes (both type 1 and type 2). The results of subjects with paranoid schizophrenia did not statistically differ from those of subjects with organic lesions of the CNS. No significant differences were found in the results of the Verbal Fluency Test between healthy subjects and patients with diabetes.

On the basis of obtained results the authors developed sten norms of the Verbal Fluency Test for the general population. Using these norms the 
authors found that subjects with paranoid schizophrenia or with organic lesions of the central nervous system had very poor results more often and very high results less frequently than did healthy subjects or patients with diabetes. Such differences were not found in the case of patients with diabetes. However, it should be noticed that the developed norms are still hypothetical and therefore the results obtained using these norms require further studies, to confirm the observed differences.

The obtained results confirm the presence of significant deficits of verbal fluency in patients with paranoid schizophrenia, whose magnitude is at least comparable to that found in patients with organic lesions of the central nervous system. Moreover, we have found that patients with diabetes (type 1 and 2) achieve results in the Verbal Fluency Test that are comparable with healthy subjects; therefore, it may be assumed that cognitive dysfunctions that are described in that population do not include disturbances of verbal fluency.

\section{Acknowledgments}

This study was supported by the Medical University of Lodz, grant no. 502-15.644.

\section{References}

1. Vlaar A, Wade D. Verbal fluency assessment of patients with multiple sclerosis: test - retest and inter-observer reliability. Clin Rehabil 2003; 17: 756-64.

2. Baldo JV, Schwartz S, Wilkins D, Dronkers NF. Role of frontal versus temporal cortex in verbal fluency as revealed by voxel-based lesion symptom mapping. J Int Neuropsychol Soc 2006; 12: 896-900.

3. Gouveia PA, Brucki SM, Malheiros SM, Bueno OF. Disorders in planning and strategy application in frontal lobe lesion patients. Brain Cogn 2007; 63: 240-6.

4. Oades RD, Bender S, Müller B, Sartory G. Neuropsychological indicators of heteromodal cortex (dys) function relevant to conditioned blocking measures of attention in schizophrenia. Cognit Neuropsychiatry 2001; 6: 41-61

5. Gaillard W, Hertz-Pennier L, Mott S, Barnett A, LeBihan D, Theodore W. Functional anatomy of cognitive development: $\mathrm{fMRI}$ of verbal fluency in children and adults. Neurology 2000; 54: 180-8.

6. Volz HP, Gaser C, Häger F, et al. Brain activation during cognitive stimulation with the Wisconsin Card Sorting Test - a functional MRI study on healthy volunteers and schizophrenics. Psych Res 1997; 75: 145-57.

7. Lipska BK, Weinberger DR. A neurodevelopmental model of schizophrenia: neonatal disconnection of the hippocampus. Neurotox Res 2002; 4: 469-75.

8. Bottlender R, Sato T, Jäger $M$, et al. The impact of the duration of untreated psychosis prior to first psychiatric admission on the 15-year outcome in schizophrenia. Schizophr Res 2003; 62: 37-44.

9. Meilijson SR, Kasher A, Elizur A. Language performance in chronic schizophrenia: a pragmatic approach. J Speech Lang Hear Res 2004; 47: 695-713.
10. Wu JH, Haan MN, Liang J, Ghosh D, Gonzalez HM, Herman WH. Impact of diabetes on cognitive function among older Latinos: a population-based cohort study. J Clin Epidemiol 2003; 56: 686-63.

11. Fontbonne A, Berr C, Ducimetière P, Alpérovitch A. Changes in cognitive abilities over a 4-year period are unfavorably affected in elderly diabetic subjects: results of the Epidemiology of Vascular Aging Study. Diabetes Care 2001; 24: 366-70.

12. Strachan MW, Deary IJ, Ewing FM, Frier BM. Recovery of cognitive function and mood after severe hypoglycemia in adults with insulin-treated diabetes. Diabetes Care 2000; 23: 305-12.

13. Vanhanen M, Koivisto K, Kuusisto J, et al. Cognitive function in an elderly population with persistent impaired glucose tolerance. Diabetes Care 1998; 21: 398-402.

14. Ott A, Stolk RP, van Harskamp F, Pols HA, Hofman A, Breteler MM. Diabetes mellitus and the risk of dementia: The Rotterdam Study. Neurology 1999; 53: 1937-42.

15. Cukierman T, Gerstein HC, Williamson JD. Cognitive decline and dementia in diabetes - systematic overview of prospective observational studies. Diabetologia 2005; 48 : 2460-9.

16. Arvanitakis Z, Wilson RS, Li Y, Aggarwal NT, Bennett DA. Diabetes and function in different cognitive systems in older individuals without dementia. Diabetes Care 2006; 29: 560-5.

17. Awad N, Gagnon M, Messier C. The relationship between impaired glucose tolerance, type 2 diabetes, and cognitive function. J Clin Exp Neuropsychol 2004; 26: 1044-80.

18. Manschot SM, Brands AM, van der Grond J, et al. Utrecht Diabetic Encephalopathy Study Group. Brain magnetic resonance imaging correlates of impaired cognition in patients with type 2 diabetes. Diabetes 2006; 55: 1106-13.

19. Talarowska M, Florkowski A, Gałecki P, Orzechowska A, Janiak M, Zboralski K. Zaburzenia funkcji poznawczych wśród chorych na cukrzycę [Polish]. Pol Merkuriusz Lek 2008; 15: 349-55.

20. Talarowska M, Florkowski A, Orzechowska A, Wysokiński A, Zboralski K. Funkcjonowanie poznawcze chorych na cukrzyce typu 1 i 2 [Polish]. Diabetol Prakt 2008; 9: 3-8.

21. Canfield A. The "sten" scale - a modified C-scale. Educ Psychol Measure 1951; 11: 295-7.

22. Lobnig B, Krömeke O, Optenhostert-Porstt C. Hippocampal volume and cognitive performance in long-standing type 1 diabetic patients without macrovascular complications. Diabet Med 2005; 23: 32-9.

23. Hsu-Ko Kuo, Jones R, Milberg W. Effect of blood pressure and diabetic mellitus and cognitive and physical functions in older adults: a longitudinal analysis of the advanced cognitive training for independent and vital elderly cohort. J Am Geriatr Soc 2005; 53: 1154-61.

24. Audenaert K, Lahorte P, Brans B, et al. The classical Stroop interferencje task as a prefrontal activation probe: a validation study using 99Tc m-ECD brain SPECT. Nucl Med Commun 2001; 22: 135-43.

25. Kumari M, Brunner E, Fuhrer R. Minireview: mechanisms by which the metabolic syndrome and diabetes impair memory. J Gerontol A Biol Sci Med Sci 2000; 55: 228-33.

26. Wysocki T, Harris M, Mauras N, Taylor A, Jackson S, White N. Absence of adverse effects of severe hypoglycemia on cognitive function in school-aged children with diabetes over 18 months. Diabetes Care 2003; 26: 1100-5.

27. Brands A, Kessels R, Hoogma R, et al. Cognitive performance, psychological well-being, and brain magnetic resonance imaging in older patients with type 1 diabetes. Diabetes 2006; 55: 1800-6. 
28. Yeung SE, Fischer AL, Dixon RA. Exploring effects of type 2 diabetes on cognitive functioning in older adults. Neuropsychology 2009; 23: 1-9.

29. Gallacher J, Pickering J, Elwood P, Bayer A, Yarnell J, BenShlomo Y. Glucoregulation has greater impact on cognitive performance than macro-vascular disease in men with type 2 diabetes: data from the Caerphilly study. Eur J Epidemiol 2005; 20: 761-8.

30. Kanaya A, Barrett-Connor E, Gildengorin G, Yaffe K. Change in cognitive function by glucose tolerance status in older adults: a 4-year prospective study of the Rancho Bernardo Study Cohort. Arch Int Med 2004; 164: 1327-33. 